\title{
Randomised phase III trial of FEC120 vs EC-docetaxel in patients with high-risk node-positive primary breast cancer: final survival analysis of the ADEBAR study
}

\begin{abstract}
W Janni ${ }^{\star}, 1,8$, N Harbeck $^{2,8}$, B Rack $^{3}$, D Augustin ${ }^{4}$, J Jueckstock $^{3}$, A Wischnik ${ }^{5}$, K Annecke ${ }^{6}$, C Scholz $^{1}$, $\mathrm{J} \mathrm{Huober}^{1}, \mathrm{~T}_{\text {Zwingers }}{ }^{7}, \mathrm{~T}$ W P Friedl ${ }^{1}$ and M Kiechle ${ }^{6}$

${ }^{1}$ Department of Gynecology and Obstetrics, University Hospital Ulm, Prittwitzstrasse 43, 89075 Ulm, Germany; ${ }^{2}$ Department of Gynecology and Obstetrics, Breast Center, Ludwig-Maximilian-University Munich, Marchioninistraße 15, 81377 München, Germany; ${ }^{3}$ Department of Gynecology and Obstetrics, Ludwig-Maximilians-University Munich, Maistraße 11, 80337 München, Germany; ${ }^{4}$ Breast Center, Department of Gynecology and Obstetrics, Hospital Deggendorf, Perlasberger Strasse 41, 94469 Deggendorf, Germany; ${ }^{5}$ Breast Center, Department of Gynecology, Klinikum Augsburg, Stenglinstrasse 2, 86156 Augsburg, Germany; ${ }^{6}$ Department of Obstetrics and Gynecology, Technical University Clinics Rechts der Isar, Ismaninger Strasse 22, 81675 München, Germany and 'Estimate GmbH, Konrad-Adenauer-Allee 1, 86150 Augsburg, Germany
\end{abstract}

Background: Taxane-containing adjuvant chemotherapy has been established as standard treatment in node-positive breast cancer. This study compared efficacy and tolerability of epirubicin (E)/cyclophosphamide (C) followed by docetaxel (Doc) with a dose-dense 5-fluorouracil (F) $+\mathrm{E}+\mathrm{C}$ regimen.

Methods: The ADEBAR study was a randomised phase III trial for women with primary invasive breast cancer and $\geqslant 4$ metastatic axillary lymph nodes $(n=1364)$. Treatment consisted of four 21-day cycles of E plus C, followed by four 21-day cycles of Doc (ECDoc), or six 28-day cycles of E plus F plus C (FEC120).

Results: Disease-free survival (DFS) was similar in the two treatment arms as shown by multivariate Cox regression adjusted for other prognostic factors (EC-Doc vs FEC120, hazard ratio (HR): 1.087; 95\% confidence interval (Cl): 0.878-1.346, $P=0.444$ ). In addition, there was no significant difference in overall survival (OS) between the two groups (HR: 0.974; $95 \%$ Cl: $0.750-1.264$, $P=0.841$ ). Haematologic toxicity was more common in FEC120 recipients; non-haematologic toxicities occurred more frequently in the EC-Doc arm. The serious adverse event rate was significantly higher in the FEC120 group (29.7\% vs $22.5 \%)$.

Conclusions: EC-Doc provides a feasible and effective alternative therapy option to FEC120 with a different safety profile in this high-risk breast cancer cohort.

Patients with early-stage breast cancer benefit from adjuvant chemotherapy in terms of reduced risk of relapse and diseaserelated death compared with no treatment (Abe et al, 2005). The benefits of anthracycline-based adjuvant chemotherapy in patients with breast cancer have been known for several decades, with meta-analysis data showing decreases in recurrence rates and mortality using these regimens compared with cyclophosphamide, methotrexate, and fluorouracil (CMF)-like combinations (Peto

\footnotetext{
*Correspondence: Professor DrW Janni; E-mail: wolfgang.janni@uniklinik-ulm.de

${ }^{8}$ These authors contributed equally to this work.
}

Received 24 August 2015; revised 2 March 2016; accepted 5 March 2016; published online 31 March 2016

(c) 2016 Cancer Research UK. All rights reserved 0007-0920/16 
et al, 2012). Most patients are eligible for anthracycline-based adjuvant chemotherapy, and the benefits are seen across a wide range of patients (Gianni et al, 2009). A conservative estimate of the absolute difference in mortality after 10 years for anthracycline vs CMF regimen is 5\% (Clarke, 2006). FEC120 (with epirubicin $60 \mathrm{mg} \mathrm{m}^{-2}$ i.v. $\mathrm{d} 1+8$, q4w, 6 cycles) has been established as one of the gold standards of anthracycline-based treatment.

Taxanes have a well-established role in the management of breast cancer (Albert et al, 2011). The majority of clinical trial data suggest that the addition of a taxane to anthracyclinebased adjuvant chemotherapy significantly improves DFS and OS compared with taxane-free anthracycline-based regimen (Henderson et al, 2003; Mamounas et al, 2005; Martin et al, 2005; Roché et al, 2006; De Laurentiis et al, 2008), with outcome improvements maintained for up to 10 years (Mackey et al, 2013). However, this has not always been the case. The MA21 trial reported lower relapse-free survival rates with an adjuvant regimen of doxorubicin/cyclophosphamide followed by paclitaxel (AC/T) compared with fluorouracil/epirubicin/cyclophosphamide (FEC) or dose-dense epirubicin/cyclosphosphamide followed by paclitaxel (EC/T) (Burnell et al, 2010). Findings such as these highlight the fact that the optimal treatment strategy for combining a taxane with anthracycline-based chemotherapy has yet to be clearly defined.

The MA21 trial utilised a dose-dense EC regimen (two epirubicin $60 \mathrm{mg} \mathrm{m}^{-2}$ doses per cycle), which may help explain the relatively lower effect of the less dose-dense AC chemotherapy schedule (Burnell et al, 2010). Although there are a large number of trials investigating the effect of adding taxanes to anthracyclinebased chemotherapy in early breast cancer, the epirubicin $120 \mathrm{mg} \mathrm{m}^{-2}$ regimen (two $60 \mathrm{mg} \mathrm{m}^{-2}$ doses each cycle) has not been widely studied in comparison with a taxane-containing regimen.

Therefore, the aim of the present study was to compare the efficacy and tolerability of sequential epirubicin/cyclophosphamide followed by docetaxel (EC-Doc) chemotherapy to an FEC regimen with an epirubicin dose of $120 \mathrm{mg} \mathrm{m}^{-2}$ per cycle (FEC120) for adjuvant treatment of women with high-risk node-positive breast cancer.

\section{PATIENTS AND METHODS}

Study design. This phase III study had a multicentre, randomised, open-label, parallel design. Randomisation was stratified on the basis of baseline prognostic variables, including metastatic axillary lymph-node involvement (4-9vs $\geqslant 10$ nodes), hormone receptor status of the primary tumour (positive $v s$ negative, with positivity defined as $\geqslant 10 \%$ stained cells for oestrogen and/or progesterone), and timing of radiotherapy (intermittently after completion of half of cytotoxic chemotherapy $v s$ after completion of the full chemotherapy course).

Eligibility. Female patients aged 18-70 years were eligible for enrolment if they met all of the following criteria: primary epithelial invasive carcinoma of the breast pT1-4, pN2-3 $(\geqslant 4$ metastatic axillary lymph nodes), pM0; complete resection of the primary tumour with resection margins free of invasive carcinoma and standard axillary lymphonodectomy $(\geqslant 10$ removed lymph nodes) not longer than 5 weeks ago; European Co-operative Oncology Group (ECOG) performance status $<2$; estimated life expectancy of $\geqslant 32$ weeks; adequate bone marrow reserve (leukocytes $\geqslant 3.0 \times 10^{9}$ per litre and platelets $\geqslant 100 \times 10^{9}$ per litre); serum levels of creatinine, aspartate aminotransferase, alanine aminotransferase, alkaline phosphatase, bilirubin, and albumin within 1.5 -fold of the normal range; intention to attend regular follow-up visits for the duration of the study; ability to understand the nature of the study. Patients were excluded if they had clinical, histopathological, or radiological evidence of distant metastases (M1), inflammatory breast cancer, previous or concomitant cytotoxic or other antineoplastic treatment which was not part of this study, a second primary malignancy (except in situ carcinoma of the cervix or adequately treated basal cell carcinoma of the skin), cardiomyopathy with impaired left ventricular (LV) function (New York Heart Association class > II), cardiac arrhythmias affecting the LV ejection fraction and requiring medication, a history of myocardial infarction or angina pectoris within the last 6 months or uncontrolled arterial hypertension, any known hypersensitivity to any medication included in the study protocol, use of any investigational agent within 3 weeks before inclusion, or if they were pregnant or breastfeeding (premenopausal women needed to be using reliable $\operatorname{method}(\mathrm{s})$ of contraception).

The study was conducted in accordance with the Declaration of Helsinki and Good Clinical Practice Guidelines. The study protocol was approved by the institutional review board of each participating study centre. All patients gave written informed consent to participate in the study.

Treatment schedule. After surgery leading to R0 resection of the primary tumour, patients were randomised to one of the following treatment arms: Arm A: four 21-day cycles of epirubicin $90 \mathrm{mg} \mathrm{m}^{-2}$ body surface area intravenously (i.v.) and cyclophosphamide $600 \mathrm{mg} \mathrm{m}^{-2}$ i.v., each administered on day 1 , followed by four 21-day cycles of docetaxel $100 \mathrm{mg} \mathrm{m}^{-2}$ i.v., administered on day 1 (EC-Doc).

Arm B: six 28-day cycles of epirubicin $60 \mathrm{mg} \mathrm{m}^{-2}$ body surface area i.v. and 5-fluorouracil $500 \mathrm{mg} \mathrm{m}^{-2}$ i.v. each administered on days 1 and 8 , plus cyclophosphamide $75 \mathrm{mg} \mathrm{m}^{-2}$, oral administration (p.o.) on days 1-14 (FEC120).

The scheduled total number of treatment cycles was eight in arm A and six in arm B, toxicity and performance status of the patients permitting. Patients with hormone receptor-positive tumours received oral tamoxifen $20 \mathrm{mg} \mathrm{day}^{-1}$ for 5 years starting at the end of chemotherapy. This could be substituted by exemestane, letrozole, or anastrozole in postmenopausal patients with contraindications to or tolerability issues with tamoxifen. Patients aged $<40$ years, with a restart of menstrual bleeding within 6 months after the completion of cytostatic treatment, or with premenopausal hormone levels received goserelin $3.6 \mathrm{mg}$ subcutaneously every 4 weeks for 2 years. Adjuvant radiotherapy was scheduled after completion of systemic chemotherapy. If patient needs or logistic issues dictated, then radiotherapy could also be administered intermittently after completion of $50 \%$ of chemotherapy cycles (i.e., after four cycles in arm A or three cycles in $\operatorname{arm} B$, respectively).

To achieve sufficient dose intensity and to prevent infections, granulocyte-colony stimulating factor (G-CSF) could be used as secondary prophylaxis in cases of febrile neutropaenia (temperature $>38.5^{\circ} \mathrm{C}$, absolute neutrophil count (ANC) $<0.5 \times 10^{9}$ per litre, requiring hospitalisation and i.v. antibiotics), neutropaenia (ANC $<0.5 \times 10^{9}$ per litre) for $>5$ days or severe neutropaenia (ANC $<0.1 \times 10^{9}$ per litre), or when the chemotherapy dosing interval needed to be prolonged due to insufficient leukocytes $\left(<3.0 \times 10^{9}\right.$ per litre) or neutrophils (ANC $<1.5 \times 10^{9}$ per litre). There was no primary prophylaxis with G-CSF in this study; secondary prophylaxis, however, was allowed. When haematological toxicities were still evident despite secondary G-CSF prophylaxis, chemotherapy doses were progressively reduced by one dose level (i.e., reduced by $25 \%$ ). If the dose had to be decreased by more than two levels, the patient was withdrawn from the study. Darbepoetin could be used to treat chemotherapyinduced anaemia (haemoglobin level $\leqslant 11.0 \mathrm{~g} \mathrm{dl}^{-1}$ or a reduction of $\geqslant 3 \mathrm{~g} \mathrm{dl}^{-1}$ within 3 months of chemotherapy). 
Study end points. The primary end point as defined in the ADEBAR study protocol was time to progression (TTP) in patients treated with FEC120 chemotherapy vs sequential ECDoc chemotherapy. The study was originally designed as a noninferiority trial and was powered (80\% power, alpha 0.05$)$ to detect inferiority of the EC-Doc chemotherapy in terms of 5-year progression-free survival rate (without deaths) in predefined strata with a non-inferiority margin of $8 \%$. However, current recommendations state that DFS rather than TTP (without deaths) should be used as an end point in adjuvant breast cancer trials (Hudis et al, 2007). Therefore, results are reported using invasive disease-free survival (IDFS, in the following only DFS) as defined according to the Standardized Definitions for Efficacy End Points (STEEP) criteria (Hudis et al, 2007) as efficacy end point (with DFS including all invasive ipsilateral, regional, contralateral and distant disease recurrences, second primary tumours, and death from any cause as events, while all non-invasive in situ cancer events were excluded). A retrospective power analysis revealed that our study with the sample size of 1364 patients had $82.2 \%$ power (two-sided test, alpha 0.05 ) to detect inferiority of the EC-Doc chemotherapy in terms of DFS with the non-inferiority margin set to an HR of 1.15. Thus, this study is sufficiently powered even if we used DFS instead of TTP as primary efficacy end point. Secondary objectives were to compare OS time after randomisation and toxicity (assessed according to the Common Toxicity Criteria of the National Cancer Institute, CTC, Version 2.0) in the two treatment groups.

Statistical considerations. The primary efficacy analysis was conducted on the full analysis set (FAS), which consisted of all patients randomised to treatment for whom data were available after randomisation. The safety population consisted of all those who received at least one dose of study medication and had data on the safety variables available.

Quantitative parameters are described by mean values, standard deviation (s.d.), minimum, median, and maximum. All analyses are based on a 5\% significance level (two-sided), with 95\% CIs calculated where appropriate. DFS and OS were calculated using Kaplan-Meier estimates and compared based on log-rank tests. The effect of prognostic factors on DFS and OS was evaluated using multivariate Cox proportional hazard models. The Chi-squared test or Fisher's exact text was used to compare categorical variables and the Mann-Whitney $U$-test was used to compare differences in continuous variables between the two treatment groups. No adjustment for multiple testing was performed. All analyses were calculated using SAS V9.1 (SAS Institute, Cary, NC, USA) or IBM SPSS Statistics V21 (IBM Corp., Armonk, NY, USA).

\section{RESULTS}

Between September 2001 and May 2005, a total of 1493 patients were randomised to treatment, 748 to EC-Doc and 745 to FEC120. The FAS consisted of 1364 patients for whom data were available (689 receiving EC-Doc and 675 receiving FEC120; see Figure 1) and the safety cohort consisted of 1358 patients (684 receiving EC-Doc and 674 receiving FEC120).

Patient characteristics. Baseline demographics and clinical characteristics are shown in Table 1. Patient characteristics after randomisation were well balanced between the two treatment arms. Median observation time was 60.6 months (95\% CI 56.9-62.8) in the EC-Doc group and 59.5 months (95\% CI 57.4-61.9) in the FEC120 group.

Treatment details. In all, $80.7 \%$ of patients in the EC-Doc group and $82.1 \%$ in the FEC120 group completed all cycles of chemotherapy ( 8 and 6 , respectively). Dose reduction was infrequent during the first cycles of chemotherapy, being necessary in $0.5 \%$ of cases in the four EC cycles and $3.2 \%$ of cases in the first three FEC120 cycles. Corresponding values for the four docetaxel cycles and cycles 4-6 of FEC120 were 5.1\% and 9.5\%, respectively.

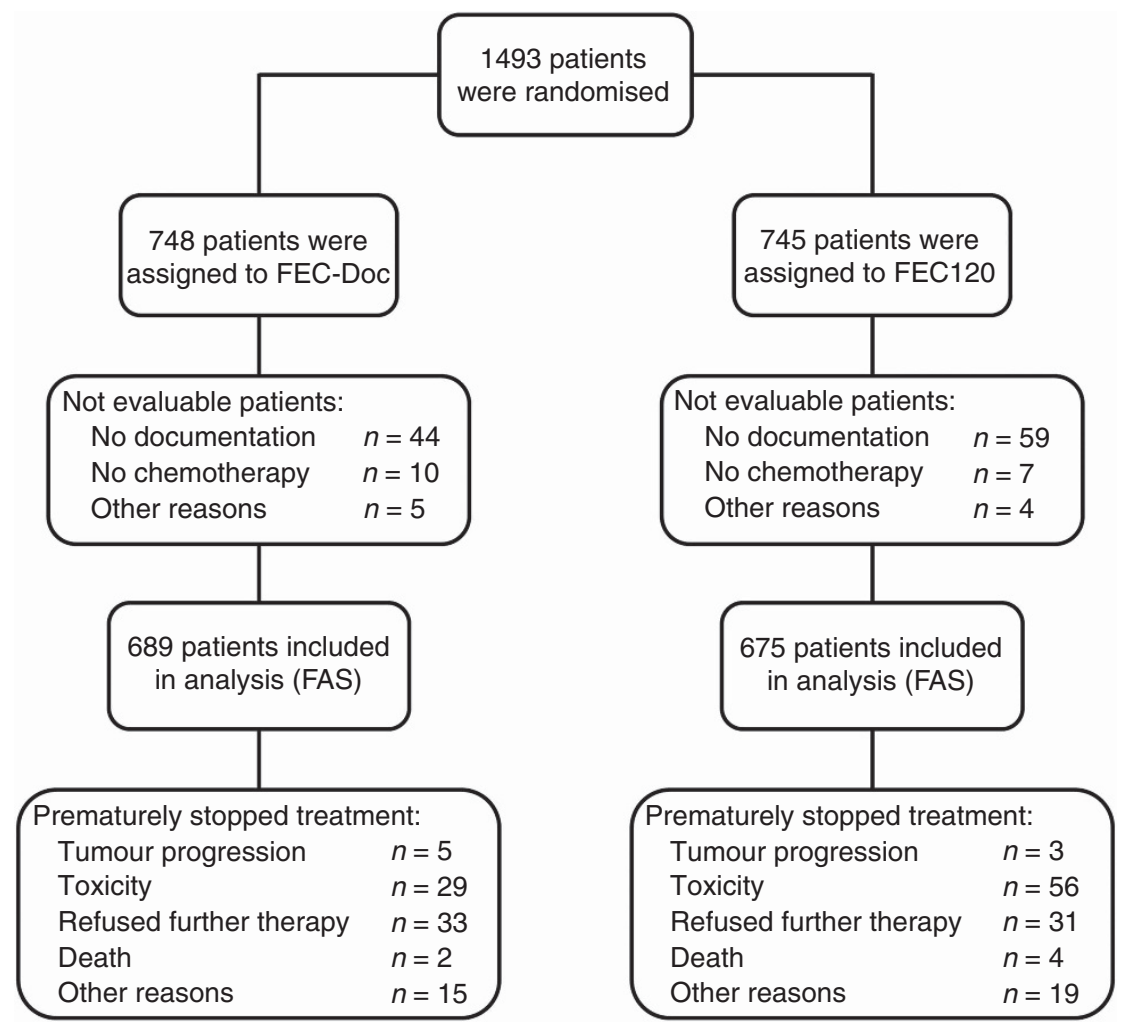

Figure 1. Consort study flowchart. 
Table 1. Patient baseline demographic data and clinical characteristics

\begin{tabular}{|c|c|c|}
\hline Variable & $\begin{array}{l}\text { EC-Doc } \\
n=689\end{array}$ & $\begin{array}{l}\text { FEC120 } \\
n=675\end{array}$ \\
\hline \multicolumn{3}{|l|}{ Age, years } \\
\hline Median (range) & $54(27-71)$ & $54(25-71)$ \\
\hline Mean (s.d.) & $53.3(9.95)$ & $53.9(9.85)$ \\
\hline \multicolumn{3}{|c|}{ Body mass index, $\mathrm{kg} \mathrm{m}^{-2}$} \\
\hline Median (range) & $25.9(15.6-53.5)$ & $25.9(16.9-48.2)$ \\
\hline Mean (s.d.) & $26.8(5.2)$ & $26.8(4.9)$ \\
\hline \multicolumn{3}{|c|}{ Menopausal status, n (\%) } \\
\hline Premenopausal & $252(36.6)$ & $253(37.5)$ \\
\hline Postmenopausal & $428(62.1)$ & $417(61.8)$ \\
\hline Unknown & 9 (1.3\%) & $5(0.7)$ \\
\hline \multicolumn{3}{|c|}{ ECOG performance status, $n(\%)$} \\
\hline 0 & $298(43.3)$ & $274(40.6)$ \\
\hline 1 & $294(42.7)$ & $303(44.9)$ \\
\hline 2 & $45(6.5)$ & $49(7.3)$ \\
\hline 3 & $3(0.4)$ & $1(0.1)$ \\
\hline 4 & $4(0.6)$ & $3(0.4)$ \\
\hline Unknown & $45(6.5)$ & $45(6.7)$ \\
\hline
\end{tabular}

Histological subtype, $n(\%)$

\begin{tabular}{|l|c|c|}
\hline Ductal & $486(70.5)$ & $467(69.2)$ \\
Lobular & $144(20.9)$ & $142(21.0)$ \\
Mixed ductal-lobular & $53(7.7)$ & $60(8.9)$ \\
Undefined & $6(0.9)$ & $6(0.9)$
\end{tabular}

Tumour location, $\mathbf{n}(\%)$

\begin{tabular}{|l|c|c|}
\hline Left & $340(49.3)$ & $343(50.8)$ \\
Right & $344(49.9)$ & $331(49.0)$ \\
Unknown & $5(0.7)$ & $1(0.1)$ \\
\hline
\end{tabular}

Tumour size, $n(\%)$

\begin{tabular}{|l|c|c|}
\hline T1 & $189(27.4)$ & $199(29.5)$ \\
T2 & $393(57.0)$ & $355(52.6)$ \\
T3 & $84(12.2)$ & $81(12.0)$ \\
T4 & $22(3.2)$ & $38(5.6)$ \\
Unknown & $1(0.1)$ & $2(0.3)$ \\
\hline
\end{tabular}

Number of positive axillary lymph nodes, $n(\%)$

\begin{tabular}{|l|c|c|}
\hline $1-3$ (pN1) & $1(0.1)$ & $3(0.4)$ \\
$4-9$ (pN2) & $417(60.5)$ & $405(60.0)$ \\
$\geqslant 10$ (pN3) & $270(39.2)$ & $265(39.3)$ \\
Unknown & $1(0.1)$ & $2(0.3)$ \\
\hline
\end{tabular}

Histological grade, $n$ (\%)

\begin{tabular}{|l|c|c|}
\hline Grade $1+2$ & $346(50.2)$ & $340(50.4)$ \\
Grade 3 & $300(43.5)$ & $274(40.6)$ \\
Unknown & $43(6.2)$ & $61(9.0)$
\end{tabular}

Hormone receptor status, $n$ (\%)

\begin{tabular}{|l|l|l|}
\hline Negative & $170(24.7)$ & $162(24.0)$ \\
Positive & $519(75.3)$ & $513(76.0)$ \\
\hline
\end{tabular}

HER2 status, $\boldsymbol{n}(\%)$

\begin{tabular}{|l|c|c|}
\hline Negative & $476(69.1)$ & $473(70.1)$ \\
Positive & $149(21.6)$ & $153(22.7)$ \\
Undefined & $64(9.3)$ & $49(7.3)$
\end{tabular}

Additional treatment, $\mathbf{n}(\%)$

\begin{tabular}{|l|l|l|}
\hline Radiotherapy after chemotherapy & 591 (85.8) & $570(84.4)$
\end{tabular}

\begin{tabular}{l|l|l} 
Radiotherapy between & $98(14.2)$ & $105(15.6)$
\end{tabular}

chemotherapy courses

Endocrine treatment

$84(12.2) \quad 73(10.8)$

Abbreviations: ECOG = European Co-operative Oncology Group; EC-Doc=epirubicin/cyclophosphamide followed by docetaxel; FEC = fluorouracil/epirubicin/cyclophosphamide.

Overall, dose reduction was necessary more often during FEC120 treatment compared with EC-Doc $(6.2 \%$ vs $2.7 \%$; $P<0.001)$. Chemotherapy was delayed in $6.2 \%$ of EC cycles, $5.6 \%$ of docetaxel cycles, and in $6.3 \%$ and $10.8 \%$ of cycles $1-3$ and $4-6$ of FEC120, respectively, with overall delay rates of $5.9 \%$ for EC-Doc and $8.5 \%$ for FEC120 $(P<0.001)$. Treatment delay following the first docetaxel cycle occurred in $6.0 \%$, which was not much higher than in the next two docetaxel cycles (5.4\% and $4.7 \%)$.

Disease-free survival. Kaplan-Meier curves displaying DFS in the two treatment groups are shown in Figure 2 for the entire study population (Figure 2A) and in subgroups of HER2-negative (Figure 2B), HER2-positive (Figure 2C), and triple-negative (Figure 2D) patients. Both for the entire study population and for the subgroups analysed, DFS was similar in patients treated with EC-Doc or FEC120. The proportion of patients with disease progression (including deaths) at 5 years was $26.0 \%$ in the EC-Doc group and $23.1 \%$ in the FEC120 group $(P=0.218)$.

Multivariate cox regressions confirmed that treatment had no significant effect on DFS (EC-Doc vs FEC120; HR 1.087; 95\% CI $0.878-1.346 ; P=0.444)$. Significant effects on DFS were found for menopausal status (post- $v$ s premenopausal; HR 1.431; 95\% CI 1.139-1.797; $P=0.002$ ), hormone-receptor status (negative vs positive; HR 1.841; 95\% CI 1.434-2.365; $P<0.001$ ), tumour size (pT3-4 vs pT1-2; HR 1.356; 95\% CI 1.036-1.773; $P=0.026$ ), number of lymph nodes involved (pN3 vs pN1-2; HR 2.126; 95\% CI $1.712-2.641 ; P<0.001$ ), and tumour grade (grade 3 vs grade $1-2$, HR 1.483; 95\% CI 1.180-1.863; $P=0.001)$.

Overall survival. There was no significant difference in OS between the EC-Doc and FEC120 groups. Overall, 134 (19.4\%) and 131 (19.4\%) patients died during follow-up in the EC-Doc group and FEC120 group, respectively. Median OS was 105.7 months in FEC120 recipients, but has not yet been reached in the EC-Doc group (logrank $P$-value for comparison between groups 0.979). As for DFS, multivariate cox regressions confirmed that treatment had no significant effect on OS (EC-Doc vs FEC120; HR 0.974; 95\% CI $0.750-1.264 ; P=0.841)$. Factors significantly associated with $\mathrm{OS}$ were menopausal status (post- $v$ s premenopausal; HR 1.560; 95\% CI 1.1762.070; $P=0.002$ ), hormone-receptor status (negative $v s$ positive; HR 2.078; 95\% CI 1.540-2.804; $P<0.001$ ), tumour size (pT3-4 vs pT1-2; HR 1.387; 95\% CI 1.001-1.922; $P=0.049$ ), number of lymph nodes involved (pN3 vs pN1-2; HR 1.951; 95\% CI 1.495-2.546; $P<0.001$ ), and tumour grade (grade 3 vs grade $1-2$; HR 1.622; 95\% CI $1.224-$ $2.150 ; P=0.001)$.

Toxicity. More than $99 \%$ of patients in both treatment groups experienced some kind of toxicity during the study. On the basis of the highest grade toxicity for each patient, the rate of grade 1-2 toxicity was $13.8 \%$ in EC-Doc recipients and $12.1 \%$ in those receiving FEC120, and the corresponding rates of grade 3-4 toxicity were $85.5 \%$ and $86.8 \%$, respectively $(P=0.952)$. The rate of serious adverse events was significantly higher in the FEC120 than in the EC-Doc group (29.7\% vs $22.5 \% ; P=0.003)$. There was also a significant difference between treatment groups in favour of EC-Doc vs FEC120 with respect to the number of patients who stopped treatment prematurely due to toxicity $(4.2 \%$ vs $8.3 \% ; P=0.002)$. In the FEC120 arm more patients received supportive treatments than in the EC-Doc arm (antibiotic treatment: 350 vs 285 patients; G-CSF support: 412 vs 273 patients; erythropoietin stimulation: 137 vs 58 patients); accordingly, rates of antibiotic treatment, G-CSF support, and erythropoietin stimulation were significantly higher in FEC120 vs EC-Doc recipients (all $P<0.001$; see Figure 3 ). In the sequential EC-Doc arm, the rate of grade $3-4$ toxicity was higher $(P<0.001)$ in the four docetaxel cycles combined (49.4\% of all cycles) than in the four EC cycles combined (37.2\%). The rate of grade 3-4 toxicity was highest in the first docetaxel cycle $(58.1 \%)$ and decreased in the following docetaxel cycles $(52.5 \%, 48.7 \%$, and $37.5 \%$ in the second, third, and fourth docetaxel cycles, respectively), which might at least partly be due to dose reductions following the first docetaxel cycle.

Most types of haematologic toxicities occurred more frequently during chemotherapy with FEC120 compared with EC-Doc (Table 2). The relative risk of grade $3-4$ anaemia $(P<0.001)$, leukopaenia $(P<0.001)$, thrombocytopaenia $(P<0.001)$, and 
A

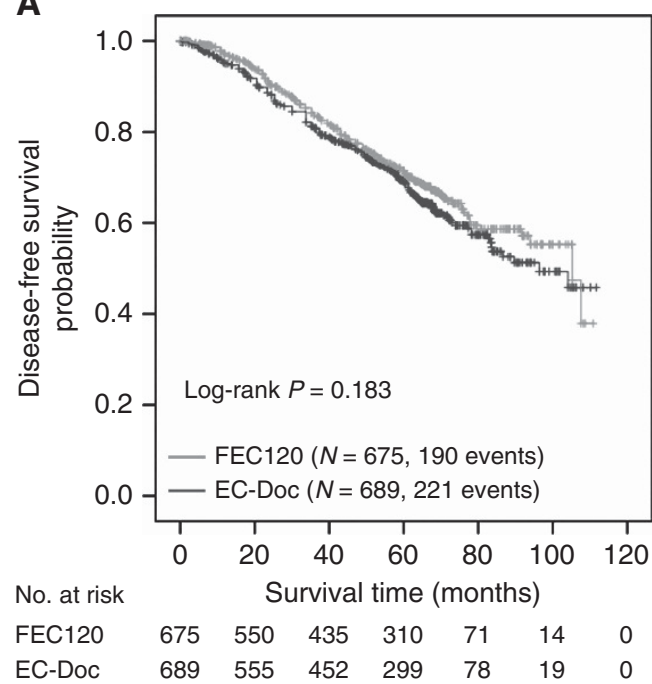

C

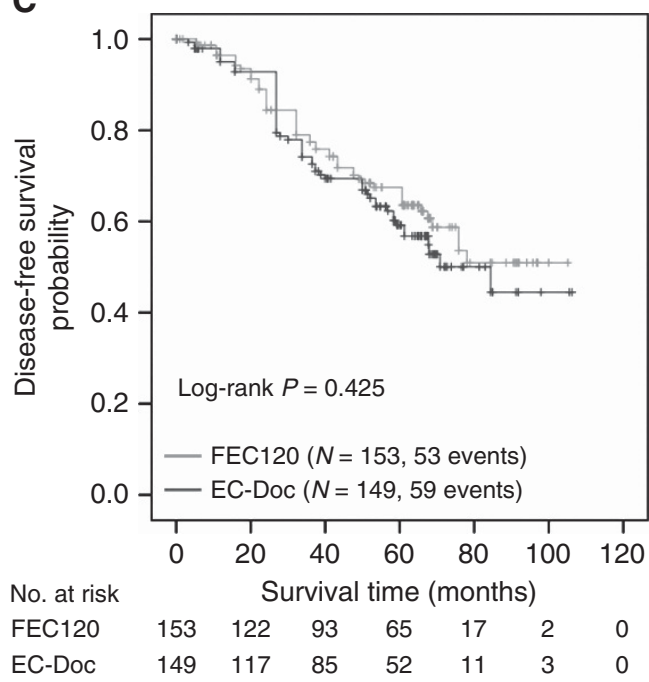

B

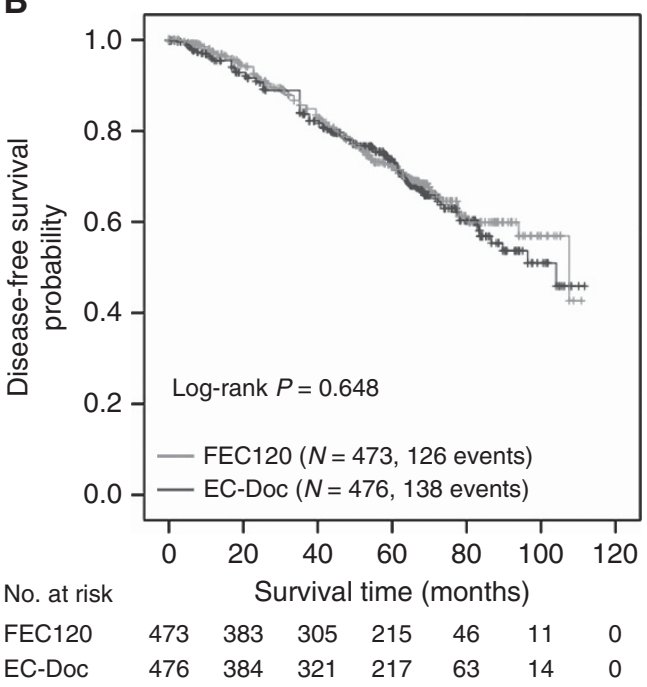

D

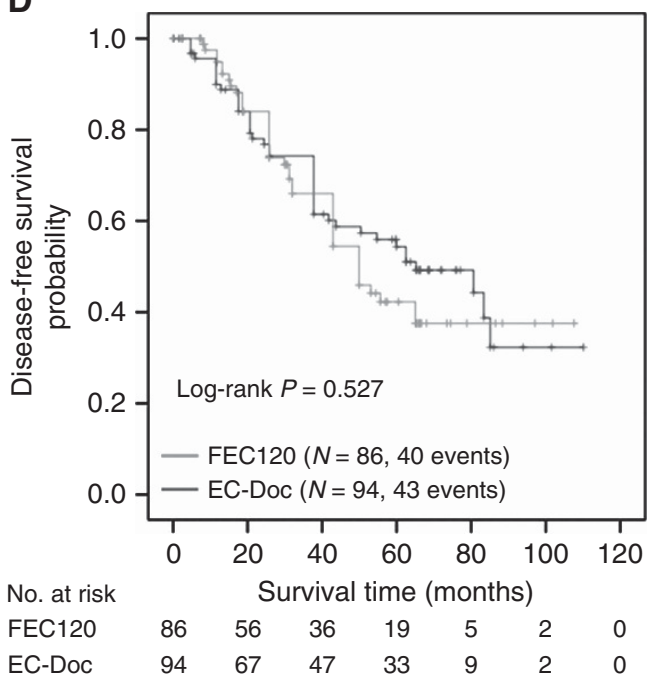

Figure 2. Disease-free survival in the full analysis set (A) and patient subgroups with HER2-negative (B), HER2-positive (C), or triple-negative (D) disease.

infection $(P=0.001)$ was significantly greater with FEC120 compared with EC-Doc. In both treatment arms, severe nonhaematologic adverse events (Table 3) were markedly less frequent than haematological toxicity. The relative risk of grade 3-4 vomiting $(P=0.004)$, oedema $(P=0.001)$, neurological symptoms $(P<0.001)$, pain $(P<0.001)$, skin reactions $(P=0.001)$, and arthralgia/myalgia $(P<0.001)$ was significantly lower with FEC120 compared with EC-Doc.

\section{DISCUSSION}

The results of the ADEBAR study did not show any significant difference in DFS and OS between high-risk node-positive breastcancer patients treated with sequential EC-Doc therapy compared with a dose-dense FEC120 regimen. The results were the same for all patients and for the subgroups of patients with HER2-positive, HER2-negative or triple-negative disease; it has to be noted, however, that the study was not sufficiently powered for these subgroup analyses. This is in line with the results of the MA21 trial that also compared dose-dense FEC120 with a sequential ECtaxane therapy (Burnell et al, 2010), but in contrast to several other previous studies that had reported improved survival outcomes by addition of a taxane to anthracycline-based chemotherapy.
Treatment with similar regimens showed improved 5-year DFS with sequential Doc then EC compared with FEC $(72.6 \%$ vs $67.2 \%$, respectively) (Polyzos et al, 2010). The order of Doc and EC therapy was opposite to that in our study, but the optimal treatment order in sequential taxane/anthracyclinebased chemotherapy has not been clearly defined (Wildiers et al, 2010) (although sequential and concurrent therapy appears to be equivalent) (Eiermann et al, 2011). There were also slight variations in drug dosages with higher $\mathrm{E}$ and lower $\mathrm{C}$ dosages in the sequential arm, and higher $\mathrm{E}$ and 5-FU and lower $\mathrm{C}$ dosages in the FEC arm of the ADEBAR study. Different drug dosages were also used in another EC-Doc vs FEC study (WSG-AGO EC-DOC), which reported significantly higher event-free survival (EFS) rates at 5 years in the sequential taxane arm vs conventionally-dosed FEC100 (89.8\% vs $87.3 \%$; $P=0.038$ ) in low-risk node-positive patients (Nitz et al, 2014), and in another trial comparing FEC100 and FEC100-Doc where 5 -year DFS was $73.2 \%$ in the standard therapy arm compared with $78.4 \%$ in the sequential taxane $\operatorname{arm}(P=0.012)$ (Roché et al, 2006). Disease-free survival was also significantly increased in patients receiving three cycles of FEC100 followed by three cycles of Doc compared with six cycles of FEC100 in the PACS01 trial $(70.2 \%$ vs 65.8\%; $P=0.03$ ) (Coudert et al, 2012), and in patients receiving FEC followed by paclitaxel compared with 


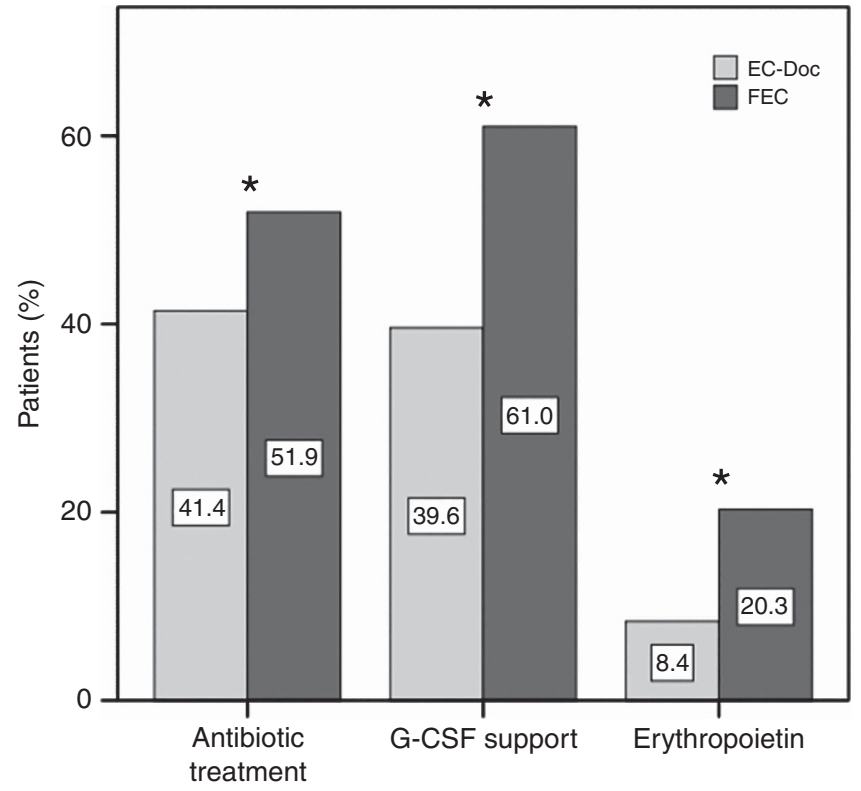

Figure 3. Use of supportive treatments during chemotherapy (G-CSF, granulocyte-colony stimulating factor; ${ }^{\star} P<0.001$ for comparison between EC-Doc and FEC120).

\section{Table 2. Haematologic toxicity}

\begin{tabular}{|c|c|c|}
\hline & $\begin{array}{c}\text { EC-Doc } \\
n=684\end{array}$ & $\begin{array}{c}\text { FEC120 } \\
n=674\end{array}$ \\
\hline \multicolumn{3}{|c|}{ Any haematologic event } \\
\hline Grade 1-2 & $98(14.3)$ & $89(13.2)$ \\
\hline Grade 3-4 & $562(82.2)$ & $567(84.1)$ \\
\hline \multicolumn{3}{|l|}{ Anaemia } \\
\hline Grade 1-2 & $540(78.9)$ & $517(76.7)$ \\
\hline Grade 3-4 & $19(2.8)$ & $105(15.6)$ \\
\hline \multicolumn{3}{|c|}{ Leukopaenia } \\
\hline Grade 1-2 & $137(20.0)$ & $93(13.8)$ \\
\hline Grade 3-4 & $491(71.8)$ & $542(80.4)$ \\
\hline \multicolumn{3}{|c|}{ Neutropaenia } \\
\hline Grade 1-2 & $82(12.0)$ & $87(12.9)$ \\
\hline Grade 3-4 & $406(59.4)$ & $420(62.3)$ \\
\hline \multicolumn{3}{|c|}{ Thrombocytopaenia } \\
\hline Grade 1-2 & $213(31.1)$ & $313(46.4)$ \\
\hline Grade 3-4 & $13(1.9)$ & $160(23.7)$ \\
\hline \multicolumn{3}{|l|}{ Infection } \\
\hline Grade 1-2 & $290(42.4)$ & $216(32.0)$ \\
\hline Grade 3-4 & $66(9.6)$ & $104(15.4)$ \\
\hline
\end{tabular}

FEC alone (5-year DFS 78.5\% vs $72.1 \%$, respectively; $P=0.006$ ) (Martín et al, 2008).

The objective end point OS is universally accepted as a direct measure of benefit in cancer trials (US Department of Health and Human Services, Food and Drug Administration, 2007). One of the studies discussed above had OS rates that were quantitatively similar to those seen in the current study, with 5 -year rates of around $80 \%$ (Polyzos et al, 2010), while in other studies, which either did (Roché et al, 2006; Nitz et al, 2014) or did not (Martín et al, 2008) show a significant difference favouring taxane-containing regimens in terms of OS, OS rates were closer to 90\% (Roché et al, 2006; Martín et al, 2008; Nitz et al, 2014), possibly reflecting variations in patient characteristics between
Table 3. Non-haematologic toxicity

\begin{tabular}{|c|c|c|}
\hline & $\begin{array}{c}\text { EC-Doc } \\
n=684\end{array}$ & $\begin{array}{c}\text { FEC1 } 20 \\
n=674\end{array}$ \\
\hline \multicolumn{3}{|c|}{ Any non-haematologic event } \\
\hline Grade 1-2 & 432 (63.2) & $520(77.2)$ \\
\hline Grade 3-4 & $247(36.1)$ & $145(21.5)$ \\
\hline \multicolumn{3}{|c|}{ Elevated bilirubin levels } \\
\hline Grade 1-2 & $0(0.0)$ & $0(0.0)$ \\
\hline Grade 3-4 & $8(1.2)$ & $1(0.1)$ \\
\hline \multicolumn{3}{|c|}{ Elevated transaminase levels } \\
\hline Grade 1-2 & $0(0.0)$ & $0(0.0)$ \\
\hline Grade 3-4 & $6(0.9)$ & $10(1.5)$ \\
\hline \multicolumn{3}{|l|}{ Nausea } \\
\hline Grade 1-2 & $3(0.4)$ & $6(0.9)$ \\
\hline Grade 3-4 & $8(1.2)$ & $11(1.6)$ \\
\hline \multicolumn{3}{|l|}{ Vomiting } \\
\hline Grade 1-2 & $0(0.0)$ & $0(0.0)$ \\
\hline Grade 3-4 & $24(3.5)$ & $12(1.8)$ \\
\hline \multicolumn{3}{|l|}{ Diarrhoea } \\
\hline Grade 1-2 & $0(0.0)$ & $0(0.0)$ \\
\hline Grade 3-4 & $7(1.0)$ & $12(1.8)$ \\
\hline \multicolumn{3}{|l|}{ Alopecia } \\
\hline Grade 1-2 & $149(21.8)$ & $252(37.4)$ \\
\hline Grade 3-4 & $4(0.6)$ & $1(0.1)$ \\
\hline \multicolumn{3}{|c|}{ Cardiac toxicity } \\
\hline Grade 1-2 & $1(0.1)$ & $0(0.0)$ \\
\hline Grade 3-4 & $1(0.1)$ & $4(0.6)$ \\
\hline \multicolumn{3}{|l|}{ Oedema } \\
\hline Grade 1-2 & $12(1.8)$ & $8(1.2)$ \\
\hline Grade 3-4 & $10(1.5)$ & $1(0.1)$ \\
\hline \multicolumn{3}{|c|}{ Neurological symptoms } \\
\hline Grade 1-2 & $8(1.2)$ & $3(0.4)$ \\
\hline Grade 3-4 & $5(0.7)$ & $1(0.1)$ \\
\hline \multicolumn{3}{|l|}{ Pain } \\
\hline Grade 1-2 & $39(5.7)$ & $31(4.6)$ \\
\hline Grade 3-4 & $35(5.1)$ & $14(2.1)$ \\
\hline \multicolumn{3}{|c|}{ Skin reactions } \\
\hline Grade 1-2 & $17(2.5)$ & $8(1.2)$ \\
\hline Grade 3-4 & $23(33.6)$ & $6(0.9)$ \\
\hline \multicolumn{3}{|c|}{ Allergic reactions } \\
\hline Grade 1-2 & $0(0.0)$ & $0(0.0)$ \\
\hline Grade 3-4 & $1(0.1)$ & $0(0.0)$ \\
\hline \multicolumn{3}{|l|}{ Fever } \\
\hline Grade 1-2 & $17(2.5)$ & $48(7.1)$ \\
\hline Grade 3-4 & $6(0.9)$ & $5(0.7)$ \\
\hline \multicolumn{3}{|c|}{ Arthralgia/myalgia } \\
\hline Grade 1-2 & $63(9.2)$ & $18(2.7)$ \\
\hline Grade 3-4 & $57(8.3)$ & $8(1.2)$ \\
\hline \multicolumn{3}{|l|}{ Mucositis } \\
\hline Grade 1-2 & $123(18.0)$ & $146(21.7)$ \\
\hline Grade 3-4 & $52(7.6)$ & $59(8.8)$ \\
\hline
\end{tabular}

studies and less advanced disease at baseline (mostly $<4$ positive lymph nodes).

Overall, it is widely accepted that adding a taxane to anthracycline-based chemotherapy regimens is beneficial, and this was documented in a comprehensive meta-analysis of clinical trials (Peto et al, 2012). The absolute 5-year risk reductions in DFS and OS by addition of a taxane have been estimated at $5 \%$ or $3 \%$, respectively (De Laurentiis et al, 2008). However, the optimal taxane-containing chemotherapy combination regimen is less 
clear. Taxane combinations that have been studied in clinical trials in early breast cancer include TAC (Mamounas et al, 2005; Mackey et al, 2013), FEC-Doc (Roché et al, 2006; Burnell et al, 2010; Polyzos et al, 2010; Coudert et al, 2012; Nitz et al, 2014), and ECDoc (Vici et al, 2012; Mirzaei et al, 2013; Sanna et al, 2013). The recent Gruppo Italiano Mammella (GIM)-2 study investigated whether 5-FU is required in taxane-containing adjuvant regimens for node-positive early breast cancer, as well as investigating the impact on outcomes of a more dose-dense regimen (treatment every 2 weeks instead of 3) (Del Mastro et al, 2015). Fluorouracil/ epirubicin/cyclophosphamide was not more effective than EC in this study, indicating that $5-\mathrm{FU}$ is not necessary in taxanecontaining adjuvant regimens, but dose-dense therapy (treatment every 2 weeks) was significantly better with respect to DFS and OS than standard therapy (treatment every 3 weeks), with or without 5-FU (Del Mastro et al, 2015).

Another study compared a sequential EC then paclitaxel chemotherapy with an intense dose-dense sequential epirubicin, paclitaxel, and cyclophosphamide (iddETC) chemotherapy in patients with high-risk node-positive ( $\geqslant 4$ positive lymph nodes) primary breast cancer, that is, the patients had a risk profile very similar to the ADEBAR trial (Moebus et al, 2010). The iddETC regimen significantly improved EFS and OS compared with the sequential EC paclitaxel regimen. The 5-year EFS and OS rates observed in the iddETC arm (EFS: 70\%; OS 82\%) were comparable to the 5 -year DFS and OS rates (71.1\% and $81.9 \%$, respectively) observed in the EC-Doc arm of the ADEBAR study, while patients in the sequential EC paclitaxel arm had 5-year EFS and OS rates of only $62 \%$ and $77 \%$ (Moebus et al, 2010).

Published studies examining anthracycline-based regimens with and without addition of a taxane are relatively consistent in showing better tolerability in the taxane-containing arms. In our study, haematological toxicity was significantly higher in patients receiving FEC120 whereas a number of non-haematological toxicities occurred at a significantly higher frequency in those treated with EC-Doc. This was similar to the toxicities observed during previous studies comparing FEC alone with FEC followed by paclitaxel treatment; haematological toxicities such as neutropaenia were significantly more common in the FEC group and non-haematological events including peripheral neuropathy, arthralgia and myalgia occurred almost exclusively in taxane recipients (Martín et al, 2008). Neurological adverse events in patients receiving taxane therapy appear to be a relatively consistent finding, being also noted in another study where Doc was administered before EC (Polyzos et al, 2010).

As described above, in our ADEBAR study, where Doc was administered after EC, the rate of haematological adverse events was lower in the taxane-containing treatment arm. This is in contrast to studies in which Doc was given before EC, where the rate of neutropaenia was significantly higher than in those studies testing standard anthracycline-based chemotherapy (Polyzos et al, 2010; Vici et al, 2012). Furthermore, a significantly greater number of Doc-EC vs FEC recipients required secondary prophylaxis with G-CSF (Polyzos et al, 2010). This is in direct contrast to our finding that rates of G-CSF support (and antibiotic treatment as well as erythropoietin stimulation) were significantly higher in FEC120 vs EC-Doc recipients. This would suggest that the order of therapy may influence the tolerability of the sequential regimen, although studies directly assessing this issue have failed to show a potential problem with tolerability when a taxane is administered first (Wildiers et al, 2010).

Cardiotoxicity is a well-known adverse effect of anthracyclines, and the cumulative dose has an important role in increasing the cardiotoxic effects of therapy (Volkova and Russell, 2011). The rate of short-term cardiac side effects in this study was very low $(<1 \%)$, but it is likely that a longer follow-up duration would be required to fully assess the negative impact of anthracyclines on the heart.
Our study has a number of limitations that should be taken into account when interpreting the results. There was some variability between patients with respect to additional treatment, such as radiotherapy and endocrine therapy. However, randomisation ensured that the treatment groups were evenly matched at baseline, and the inclusion of a broad range of patients means that the results are more likely to be applicable to the diversity of cases encountered in clinical practice. In addition, the large number of patients included in the study and the similarity of results across patient subgroups suggests that the study results can be considered robust. The study included patients with $>3$ lymph-node metastases; and therefore, the results are only valid in this subgroup of breast cancer patients. In addition, the findings cannot be generalised to elderly patients, who were not part of the patient population studied. It should also be noted that the FEC120 comparator used in this study represents an intense regimen with relatively high levels of efficacy (and therefore sets high comparative standards) but these come at the cost of increased levels of toxicity; and therefore, FEC120 is not always considered as an appropriate treatment option. Finally, it has to be emphasised that patients with HER2-positive tumours did not receive HER2targeted treatment, as trastuzumab was not approved for treatment of early breast cancer at the time of the ADEBAR study. Trastuzumab might affect efficacy of cytotoxic therapies, and the addition of trastuzumab to adjuvant chemotherapy seems to offset the advantage of anthracycline $v s$ non-anthracycline regimen (Slamon et al, 2011). However, we found no difference in survival between the two anthracycline-based treatments FEC120 and ECDoc in patients with HER2-positive disease, and there is no evidence suggesting that trastuzumab efficacy differs between anthracycline-based chemotherapies with or without taxanes.

The ADEBAR study adds to the body of evidence supporting sequential administration of anthracycline-based chemotherapy and taxanes. This approach allows the dose intensity and/or cumulative drug doses to be maximised without unmanageable or intolerable toxicity. Both regimens are obviously very effective for the adjuvant therapy of patients with high-risk node-positive breast cancer. Thus, knowledge about their equivalence in terms of efficacy means the most appropriate regimen can be selected for individual patients. Furthermore, differences in toxicity between the regimens could aid in the decision-making process when clinicians are deciding on the best overall option for their patient. Another factor to consider is that regimens containing Doc rather than 5 -FU in combination with an anthracycline and cyclophosphamide might have advantages in terms of cost-effectiveness based on the results of a Spanish study (Martín-Jiménez et al, 2009). Clinical outcomes from the BCIRG001 trial were used in the development of a Markov model which generated cost-effectiveness ratios of $€ 2345$ and $€ 2631$ per life-year and quality-adjusted life-year gained, respectively, for treatment of node-positive breast cancer with Doc, doxorubicin, and cyclosphosphamide vs 5-flourouracil, doxorubicin, and cyclosphosphamide (MartínJiménez et al, 2009). There is also a possibility that medical costs could be lower with the taxane-based regimen due to less intervention required for haematologic toxicity.

In conclusion, both EC-Doc and dose-dense FEC120 are feasible and effective regimens for the treatment of patients with high-risk node-positive early breast cancer, with a similar effect on DFS and OS. The different tolerability profiles of the two anthracyclinebased regimens favour EC-Doc for the majority of patients.

\section{ACKNOWLEDGEMENTS}

We would like to thank professional medical writer Nicola Ryan of Rata Communications for assistance with preparation of the 
manuscript, all the centers who recruited patients to the ADEBAR study, and last but not least all the patients who agreed to participate in this trial. Research support was provided by SanofiAventis, Astra-Zeneca, Amgen, Wilex, and Novartis. The corresponding author had full access to the study data and had final responsibility for data interpretation, manuscript content, and the decision to submit for publication.

\section{CONFLICT OF INTEREST}

WJ received research grants from Novartis, GSK, Amgen, Eisai, Roche, Teva, Pierre Fabre, and Janssen Diagnostics. BR received research grants from Sanofi-Aventis, Astra-Zeneca, Amgen, and Novartis and is on the advisory board of Amgen and Novartis. JH is on the advisory board of Sanofi-Aventis.

\section{AUTHOR CONTRIBUTIONS}

WJ, $\mathrm{NH}$, and $\mathrm{MK}$ contributed to conception and design and study supervision. WJ, NH, BR, DA, JJ, AW, KA, CS, JH, and MK contributed to acquisition of data. WJ, NH, TZ, TWPF, and MK contributed to analysis and interpretation of data. WJ, NH, BR, $\mathrm{DA}, \mathrm{JJ}, \mathrm{AW}, \mathrm{KA}, \mathrm{CS}, \mathrm{JH}, \mathrm{TZ}, \mathrm{TWPF}$, and MK contributed to writing, review, and/or revision of the manuscript.

\section{REFERENCES}

Abe O, Abe R, Enomoto K, Kikuchi K, Koyama H, Masuda H, Nomura Y, Sakai K, Sugimachi K, Tominaga T, Uchino J, Yoshida M, Haybittle JL, Davies C, Harvey VJ, Holdaway TM, Kay RG, Mason BH, Forbes JF, Wilcken N, Gnant M, Jakesz R, Ploner M, Yosef HMA, Focan C, Lobelle JP, Peek U, Oates GD, Powell J, Durand M, Mauriac L, Di Leo A, Dolci S, Piccart MJ, Masood MB, Parker D, Price JJ, PSGJ Hupperets, Jackson S, Ragaz J, Berry D, Broadwater G, Cirrincione C, Muss H, Norton L, Weiss RB, Abu-Zahra HT, Portnoj SM, Baum M, Cuzick J, Houghton J, Riley D, Gordon NH, Davis HL, Beatrice A, Mihura J, Naja A, Lehingue Y, Romestaing P, Dubois JB, Delozier T, Mace-Lesec'h J, Rambert P, Andrysek O, Barkmanova J, Owen JR, Meier P, Howell A, Ribeiro GC, Swindell R, Alison R, Boreham J, Clarke M, Collins R, Darby S, Elphinstone P, Evans V, Godwin J, Gray R, Harwood C, Hicks C, James S, MacKinnon E, McGale P, McHugh T, Mead G, Peto R, Wang Y, Albano J, de Oliveira CF, Gervasio H, Gordilho J, Johansen H, Mouridsen HT, Gelman RS, Harris JR, Henderson IC, Shapiro CL, Andersen KW, Axelsson CK, Blichert-Toft M, Moller S, Overgaard J, Overgaard M, Rose C, Cartensen B, Palshof T, Trampisch HJ, Dalesio O, de Vries EGE, Rodenhuis S, van Tinteren H, Comis RL, Davidson NE, Robert N, Sledge G, Tormey DC, Wood W, Cameron D, Chetty U, Forrest P, Jack W, Rossbach J, Klijn JGM, Treurniet-Donker AD, van Putten WLJ, Costa A, Veronesi U, Bartelink H, Duchateau L, Legrand C, Sylvester R, van der Hage JA, van de Velde CJH, Cunningham MP, Catalano R, Creech RH, Bonneterre J, Fargeot P, Fumoleau P, Kerbrat P, Namer M, Jonat W, Kaufmann M, Schumacher M, von Minckwitz G, Bastert G, Rauschecker H, Sauer R, Sauerbrei W, Schauer A, de Schryver A, Vakaet L, Belfiglio M, Nicolucci A, Pellegrini F, Sacco M, Valentini M, McArdle CS, Smith DC, Galligioni E, Boccardo F, Rubagotti A, Dent DM, Gudgeon CA, Hacking A, Erazo A, Medina JY, Izuo M, Morishita Y, Takei H, Fentiman IS, Hayward JL, Rubens RD, Skilton D, Graeff H, Janicke F, Meisner C, Scheurlen H, von Fournier D, Dafni U, Fountzilas G, Klefstrom P, Blomqvist C, Saarto T, Margreiter R, Asselain B, Salmon RJ, Vilcoq JR, Arriagada R, Hill C, Laplanche A, Le MG, Spielmann M, Bruzzi P, Montanaro E, Rosso R, Sertoli MR, Venturini M, Amadori D, Benraadt J, Kooi M, van de Velde AO, van Dongen JA, Vermorken JB, Castiglione M, Cavalli F, Coates A, Collins J, Gelber RD, Goldhirsch A, Lindtner J, Price KN, Rudenstam CM, Senn HJ, Bliss JM, Chilvers CED, Coombes RC, Hall E, Marty M, Borovik R, Brufman G, Hayat H, Robinson E, Wigler N, Bonadonna G, Camerini T, De Palo G, Del Vecchio M, Formelli F, Valagussa P, Martoni A, Pannuti F,
Cocconi G, Colozza A, Camisa R, Aogi K, Takashima S, Ikeda T, Inokuchi K, Sawa K, Sonoo H, Korzeniowski S, Skolyszewski J, Ogawa M, Yamashita J, Bonte J. Early Breast Cancer Trialists' Collaborative Group (EBCTCG) (2005) Effects of chemotherapy and hormonal therapy for early breast cancer on recurrence and 15-year survival: an overview of the randomised trials. Lancet 365: 1687-1717.

Albert JM, Buzdar AU, Guzman R, Allen PK, Strom Ea, Perkins GH, Woodward Wa, Hoffman KE, Tereffe W, Hunt KK, Buchholz Ta, Oh JL (2011) Prospective randomized trial of 5-fluorouracil, doxorubicin, and cyclophosphamide (FAC) vs paclitaxel and FAC (TFAC) in patients with operable breast cancer: Impact of taxane chemotherapy on locoregional control. Breast Cancer Res Treat 128: 421-427.

Burnell M, Levine MN, Chapman JW, Bramwell V, Gelmon K, Walley B, Vandenberg T, Chalchal H, Albain KS, Perez EA, Rugo H, Pritchard K, Brien PO, Shepherd LE (2010) Cyclophosphamide, epirubicin, and fluorouracil $v s$ dose-dense epirubicin and cyclophosphamide followed by paclitaxel $v s$ doxorubicin and cyclophosphamide followed by paclitaxel in node-positive or high-risk node-negative breast cancer. J Clin Oncol 28: $77-82$.

Clarke M (2006) Meta-analyses of adjuvant therapies for women with early breast cancer: The Early Breast Cancer Trialists' Collaborative Group overview. Ann Oncol 17: 59-62.

Coudert B, Asselain B, Campone M, Spielmann M, Machiels J-P, Pénault-Llorca F, Serin D, Lévy C, Romieu G, Canon J-L, Orfeuvre H, Piot G, Petit T, Jerusalem G, Audhuy B, Veyret C, Beauduin M, Eymard J-C, Martin A-L, Roché H (2012) Extended benefit from sequential administration of docetaxel after standard fluorouracil, epirubicin, and cyclophosphamide regimen for node-positive breast cancer: the 8-year follow-up results of the UNICANCER-PACS01 trial. Oncologist 17: 900-909.

Eiermann W, Pienkowski T, Crown J, Sadeghi S, Martin M, Chan A, Saleh M, Sehdev S, Provencher L, Semiglazov V, Press M, Sauter G, Lindsay M-A, Riva A, Buyse M, Drevot P, Taupin H, Mackey JR (2011) Phase III study of doxorubicin/cyclophosphamide with concomitant $v s$ sequential docetaxel as adjuvant treatment in patients with human epidermal growth factor receptor 2-normal, node-positive breast cancer: BCIRG-005 trial. J Clin Oncol 29: 3877-3884.

Gianni L, Norton L, Wolmark N, Suter TM, Bonadonna G, Hortobagyi GN (2009) Role of anthracyclines in the treatment of early breast cancer. J Clin Oncol 27: 4798-4808.

Henderson IC, Berry DA, Demetri GD, Cirrincione CT, Goldstein LJ, Martino S, Ingle JN, Cooper MR, Hayes DF, Tkaczuk KH, Fleming G, Holland JF, Duggan DB, Carpenter JT, Frei E, Schilsky RL, Wood WC, Muss HB, Norton L (2003) Improved outcomes from adding sequential paclitaxel but not from escalating doxorubicin dose in an adjuvant chemotherapy regimen for patients with node-positive primary breast cancer. J Clin Oncol 21: 976-983.

Hudis CA, Barlow WE, Costantino JP, Gray RJ, Pritchard KI, Chapman JAW, Sparano JA, Hunsberger S, Enos RA, Gelber RD, Zujewski JA (2007) Proposal for standardized definitions for efficacy end points in adjuvant breast cancer trials: the STEEP system. J Clin Oncol 25: 2127-2132.

De Laurentiis M, Cancello G, D’Agostino D, Giuliano M, Giordano A, Montagna E, Lauria R, Forestieri V, Esposito A, Silvestro L, Pennacchio R, Criscitiello C, Montanino A, Limite G, Bianco AR, De Placido S (2008) Taxane-based combinations as adjuvant chemotherapy of early breast cancer: a meta-analysis of randomized trials. J Clin Oncol 26: 44-53.

Mackey JR, Martin M, Pienkowski T, Rolski J, Guastalla J-P, Sami A, Glaspy J, Juhos E, Wardley A, Fornander T, Hainsworth J, Coleman R, Modiano MR, Vinholes J, Pinter T, Rodríguez-Lescure A, Colwell B, Whitlock P, Provencher L, Laing K, Walde D, Price C, Hugh JC, Childs BH, Bassi K, Lindsay M-A, Wilson V, Rupin M, Houé V, Vogel C (2013) Adjuvant docetaxel, doxorubicin, and cyclophosphamide in node-positive breast cancer: 10-year follow-up of the phase 3 randomised BCIRG 001 trial. Lancet Oncol 14: 72-80.

Mamounas EP, Bryant J, Lembersky B, Fehrenbacher L, Sedlacek SM, Fisher B, Wickerham DL, Yothers G, Soran A, Wolmark N (2005) Paclitaxel after doxorubicin plus cyclophosphamide as adjuvant chemotherapy for node-positive breast cancer: results from NSABP B-28. J Clin Oncol 23: 3686-3696.

Martin M, Pienkowski T, Mackey J, Pawlicki M, Guastalla J-P, Weaver C, Tomiak E, Al-Tweigeri T, Chap L, Juhos E, Guevin R, Howell A, Fornander T, Hainsworth J, Coleman R, Vinholes J, Modiano M, Pinter T, Tang SC, Colwell B, Prady C, Provencher L, Walde D, 
Rodriguez-Lescure A, Hugh J, Loret C, Rupin M, Blitz S, Jacobs P, Murawsky M, Riva A, Vogel C (2005) Adjuvant docetaxel for nodepositive breast cancer. $N$ Engl J Med 352: 2302-2313.

Martín M, Rodríguez-Lescure Á, Ruiz A, Alba E, Calvo L, Ruiz-Borrego M, Munárriz B, Rodríguez Ca, Crespo C, De Alava E, López García-Asenjo JA, Guitián MD, Almenar S, González-Palacios JF, Vera F, Palacios J, Ramos M, Gracia Marco JM, Lluch A, Alvarez I, Seguí MA, Mayordomo JI, Antón A, Baena JM, Plazaola A, Modolell A, Pelegrí A, Mel JR, Aranda E, Adrover E, Álvarez JV, García Puche JL, Sánchez-Rovira P, Gonzalez S, López-Vega JM (2008) Randomized phase 3 trial of fluorouracil, epirubicin, and cyclophosphamide alone or followed by paclitaxel for early breast cancer. J Natl Cancer Inst 100: 805-814.

Martín-Jiménez M, Rodríguez-Lescure A, Ruiz-Borrego M, Seguí-Palmer M-A, Brosa-Riestra M (2009) Cost-effectiveness analysis of docetaxel (Taxotere) $v s$-fluorouracil in combined therapy in the initial phases of breast cancer. Clin Transl Oncol 11: 41-47.

Del Mastro L, De Placido S, Bruzzi P, De Laurentiis M, Boni C, Cavazzini G, Durando A, Turletti A, Nisticò C, Valle E, Garrone O, Puglisi F, Montemurro F, Barni S, Ardizzoni A, Gamucci T, Colantuoni G, Giuliano M, Gravina A, Papaldo P, Bighin C, Bisagni G, Forestieri V, Cognetti F (2015) Fluorouracil and dose-dense chemotherapy in adjuvant treatment of patients with early-stage breast cancer: an open-label, $2 \times 2$ factorial, randomised phase 3 trial. Lancet (London, England) 385: $1863-1872$.

Mirzaei HR, Sabet Rasekh P, Nasrollahi F, Sabet Rasekh P, Akbari Tirabad Z, Moein HR, Ghaffari Pour T, Hajian P (2013) Dose-dense epirubicin and cyclophosphamide followed by docetaxel as adjuvant chemotherapy in node-positive breast cancer. Int J Breast Cancer 2013: 404396.

Moebus V, Jackisch C, Lueck HJ, Du Bois A, Thomssen C, Kurbacher C, Kuhn W, Nitz U, Schneeweiss A, Huober J, Harbeck N, Von Minckwitz G, Runnebaum IB, Hinke A, Kreienberg R, Konecny GE, Untch M (2010) Intense dose-dense sequential chemotherapy with epirubicin, paclitaxel, and cyclophosphamide compared with conventionally scheduled chemotherapy in high-risk primary breast cancer: mature results of an AGO phase III study. J Clin Oncol 28: 2874-2888.

Nitz U, Gluz O, Huober J, Kreipe HH, Kates RE, Hartmann A, Erber R, Scholz M, Lisboa B, Mohrmann S, Möbus V, Augustin D, Hoffmann G, Weiss E, Böhmer S, Kreienberg R, Du Bois A, Sattler D, Thomssen C, Kiechle M, Jänicke F, Wallwiener D, Harbeck N, Kuhn W (2014) Final analysis of the prospective WSG-AGO EC-Doc $v s$ FEC phase III trial in intermediate-risk (pN1) early breast cancer: Efficacy and predictive value of Ki67 expression. Ann Oncol 25: 1551-1557.

Peto R, Davies C, Godwin J, Gray R, Pan HC, Clarke M, Cutter D, Darby S, McGale P, Taylor C, Wang YC, Bergh J, Di Leo A, Albain K, Swain S, Piccart M, Pritchard K, Anderson S, Arriagada R, Barlow W, Bliss J, Buyse M, Cameron D, Carrasco E, Correa C, Coates A, Collins R, Costantino J, Cuzick J, Davidson N, Davies K, Delmestri A, Dowsett M, Elphinstone P, Evans V, Ewertz M, Gelber R, Gettins L, Geyer C, Goldhirsch A, Gregory C, Hayes D, Hill C, Ingle J, Jakesz R, James S, Kaufmann M, Kerr A, MacKinnon E, McHugh T, Norton L, Ohashi Y, Paik S, Perez E, Pierce L, Pruneri G, Raina V, Ravdin P, Robertson J,
Rutgers E, Shao YF, Valagussa P, Viale G, Whelan T, Winer E, Wood W (2012) Comparisons between different polychemotherapy regimens for early breast cancer: meta-analyses of long-term outcome among 100000 women in 123 randomised trials. Lancet 379: 432-444.

Polyzos A, Malamos N, Boukovinas I, Adamou A, Ziras N, Kalbakis K, Kakolyris S, Syrigos K, Papakotoulas P, Kouroussis C, Karvounis N, Vamvakas L, Christophyllakis C, Athanasiadis A, Varthalitis I, Georgoulias V, Mavroudis D (2010) FEC vs sequential docetaxel followed by epirubicin/cyclophosphamide as adjuvant chemotherapy in women with axillary node-positive early breast cancer: a randomized study of the Hellenic Oncology Research Group (HORG). Breast Cancer Res Treat 119: 95-104.

Roché H, Fumoleau P, Spielmann M, Canon JL, Delozier T, Serin D, Symann M, Kerbrat P, Soulié P, Eichler F, Viens P, Monnier A, Vindevoghel A, Campone M, Goudier MJ, Bonneterre J, Ferrero JM, Martin AL, Genève J, Asselain B (2006) Sequential adjuvant epirubicinbased and docetaxel chemotherapy for node-positive breast cancer patients: The FNCLCC PACS 01 trial. J Clin Oncol 24: 5664-5671. Sanna G, Pestrin M, Zafarana E, Biagioni C, Cavaciocchi D, Turner N, Di Leo A, Biganzoli L (2013) Feasibility and safety of dose-dense docetaxel after conventional epirubicin and cyclophosphamide as adjuvant treatment for early breast cancer patients. Breast 22: 926-932.

Slamon D, Eiermann W, Robert N, Pienkowski T, Martin M, Press M, Mackey J, Glaspy J, Chan A, Pawlicki M, Pinter T, Valero V, Liu M-C, Sauter G, von Minckwitz G, Visco F, Bee V, Buyse M, Bendahmane B, Tabah-Fisch I, Lindsay M-A, Riva A, Crown J (2011) Adjuvant trastuzumab in HER2-positive breast cancer. N Engl J Med 365: 1273-1283.

US Department of Health and Human Services, Food and Drug Administration (2007) Guidance for Industry: Clinical Trial Endpoints for the Approval of Cancer Drugs and Biologics. Available from http://www.fda.gov/downloads/Drugs/Guidance ComplianceRegulatoryInformation/Guidances/UCM071590.pdf.

Vici P, Brandi M, Giotta F, Foggi P, Schittulli F, Di lauro L, Gebbia N, Massidda B, Filippelli G, Giannarelli D, Di benedetto A, Mottolese M, Colucci G, Lopez M (2012) A multicenter phase III prospective randomized trial of high-dose epirubicin in combination with cyclophosphamide (EC) vs docetaxel followed by EC in node-positive breast cancer. GOIM (Gruppo Oncologico Italia Meridionale) 9902 study. Ann Oncol 23: 1121-1129.

Volkova M, Russell R (2011) Anthracycline cardiotoxicity: prevalence, pathogenesis and treatment. Curr Cardiol Rev 7: 214-220.

Wildiers H, Forceville K, Paridaens R, Joensuu H (2010) Taxanes and anthracyclines in early breast cancer: which first? Lancet Oncol 11: 219-220.

This work is published under the standard license to publish agreement. After 12 months the work will become freely available and the license terms will switch to a Creative Commons AttributionNonCommercial-Share Alike 4.0 Unported License. 